\title{
Use of a Mechanical Labor Simulator in Medical Student Education
}

\author{
Amy J Ravin ${ }^{1 *}$, Sheran N Fernando ${ }^{2}$ and Jeffrey A Gavard ${ }^{3}$ \\ ${ }^{1}$ Assistant Professor, St. Louis University, USA \\ ${ }^{2}$ PhD candidate, Lakehead University, USA \\ ${ }^{3}$ Department of Obstetrics, Gynecology and Women's Health, St. Louis University, USA
}

Submission: January 10, 2018; Published: April 30, 2018

*Corresponding author: Amy J Ravin, Assistant Professor, St. Louis University, 6420 Clayton Rd, Suite 242 Richmond Heights, MO 63117, Missouri, USA, Tel: 314781-1505; Email: ravin@slu.edu

\section{Abstract}

Introduction: To determine if a relatively inexpensive (\$895) mechanical birth simulator is effective for teaching third year medical students about normal labor and delivery and to evaluate its effect on their confidence to perform a vaginal delivery. Simulators have been shown to improve student confidence and knowledge during obstetric clerkships.

Methods: This was an observational trial of thirty-nine medical students rotating through their obstetrics, gynecology and women's health clerkship at an academic medical center who participated in an educational innovation using a mechanical birth simulator. Obstetric knowledge and confidence were measured pre- and post-simulation training using questionnaires.

Results: Forty-three students were approached about participating in an educational innovation. All agreed to participate. Thirty-nine had complete pre- and post-simulation training questionnaires and were therefore included in the analysis. The majority (39) were third year medical students; four were fourth year subinterns. Twelve had completed their labor and delivery rotation, 28 were currently on the rotation and three students had not yet had any labor and delivery experience. Thirty-nine of the 43 (90.7\%) students completed pre- and post-simulation training questionnaires and were included in the analysis. Simulator training resulted in an improvement in obstetrical knowledge on all questions asked $(\mathrm{P}<0.001)$ and an improvement in student confidence for all scenarios presented $(\mathrm{P}<0.001)$.

Conclusion: A simple mechanical birth simulator is practical, engaging and cost-effective for teaching third year medical students about normal labor and delivery. It resulted in improved student knowledge and confidence.

Keywords: Simulator; Mechanical labor; Normal labor; Birth simulator; Vaginal delivery; Risk free; Repeated practice; Pedagogical; Female pelvic skeleton; Model fetus; Birthing torso; Bony pelvis; Anonymous; Obstetric lacerations; Cardinal movements; Post-simulation; Statistically significant; Electronic; High fidelity simulators; Varying degrees; Obstetrical knowledge

\section{Introduction}

Simulation training has emerged as a novel teaching solution in third year medical student clerkship training. Simulation can allow for a risk free experience, repeated practice and learning prior to working with patients. Simulator training has been shown to improve medical student confidence in their abilities to perform a vaginal delivery [1-3]. Simulation has also been shown to improve oral and written exam scores for third year medical students [4], and to increase participation in deliveries during the third year clerkship [3]. However, all but one of these studies exclusively used an electronic birth simulator. The cost of electronic simulators ranges from several thousand to tens of thousands of dollars which may limit their widespread use in undergraduate medical teaching. The purpose of our study was to determine if the use of less expensive, simpler, mechanical birth simulator could similarly increase student confidence and knowledge about normal vaginal delivery.

\section{Materials and Methods}

We were selected to receive a 2013 Try It! Summer MiniGrant through the Paul C. Reinert, S.J. Center for Transformative Teaching and Learning At St. Louis University. These grants of up to $\$ 1,500$ are intended to fund small-scale pedagogical projects that can have an immediate impact on student learning and engagement at St. Louis University. With this funding we purchased a plastic model of the bony pelvis and a model fetus. Additionally, we obtained a model torso/pelvis that can simulate labor and delivery (S500.100 Ob Susie, Gaumard, Miami, FL). Total cost before shipping and handling \$1,036 which included the female pelvic skeleton (\$77), model fetus (\$64) and light weight birthing torso (\$895). This study was approved by the St. Louis University Institutional Review Board as exempt.

Medical students participating in the obstetrics and gynecology rotation at SSM Health St. Mary's Hospital from 


\section{Global Journal of Reproductive Medicine}

July to December 2013 were asked if they were willing to participate in the educational initiative. The participants were a convenience sample of available students. They were divided into groups of 3-5 students for 1.5-2.5 hour sessions. The models were used to teach pelvic anatomy, the cardinal movement of labor, and provide a simulation of labor and delivery. Each student went through the process of delivery with the model bony pelvis and the mechanical torso model. To evaluate the success of the new teaching tool, we used a standardized questionnaire to test student knowledge of the stages of labor, types of obstetric lacerations, and the cardinal movements of labor. All questionnaires were anonymous with no identifying name or date. Students were told the questionnaires had no bearing on their evaluations for the rotation. The questionnaires were administered before and after the simulation exercise to measure the effects of the simulation. Additionally, the students were asked about their knowledge and readiness to participate in a delivery before and after the simulation. This was based on previously published studies of the use of a simulator [1,4]. Finally, a questionnaire was given to evaluate how useful the medical students found the simulation exercise.

\section{Statistical analysis}

Questions assessing knowledge of the stages of labor, types of obstetric lacerations, and cardinal movements of labor were open-ended questions where students were asked to write in their answers. The number of correct answers was compared between the pre- and post-simulation questionnaire. A student had to correctly define all three stages of labor, all four types of obstetric lacerations, and all cardinal movements of labor to be coded as a correct answer. Partially correct answers were coded as incorrect. Changes in knowledge of stages of labor, types of

Table 1: Change in Knowledge of Stages of Labor, Lacerations, and Cardinal Movements of Labor for $43^{*}$ Medical Students.

\begin{tabular}{|c|c|c|c|c|c|c|c|}
\hline \multicolumn{8}{|c|}{ Stages of Labor } \\
\hline \multirow[t]{2}{*}{ Pre-Simulation Training } & \multicolumn{4}{|c|}{ Post-Simulation Training } & \multicolumn{2}{|c|}{ Total } & \multirow[t]{2}{*}{ P-value } \\
\hline & Correct & & Incorrect & & & & \\
\hline & $\mathbf{n}$ & $\%$ & $\mathbf{n}$ & $\%$ & $\mathbf{n}$ & $\%$ & \\
\hline Correct & 15 & 100 & 0 & 0 & 15 & 100 & $<0.001 \dagger$ \\
\hline Incorrect & 16 & 66.7 & 8 & 33.3 & 24 & 100 & \\
\hline \multicolumn{8}{|c|}{ Types of Lacerations } \\
\hline \multirow[t]{3}{*}{ Pre-Simulation Training } & \multicolumn{4}{|c|}{ Post-Simulation Training } & \multicolumn{2}{|c|}{ Total } & P-value \\
\hline & Correct & & Incorrect & & & & \\
\hline & $\mathbf{n}$ & $\%$ & $\mathbf{n}$ & $\%$ & n & $\%$ & \\
\hline Correct & 5 & 100 & 0 & 0 & 5 & 100 & $<0.001 \dagger$ \\
\hline Incorrect & 24 & 70.6 & 10 & 29.4 & 34 & 100 & \\
\hline \multicolumn{8}{|c|}{ Cardinal Movements of Labor } \\
\hline \multirow[t]{3}{*}{ Pre-Simulation Training } & \multicolumn{4}{|c|}{ Post-Simulation Training } & \multicolumn{2}{|c|}{ Total } & P-value \\
\hline & Correct & & Incorrect & & & & \\
\hline & $\mathrm{n}$ & $\%$ & $\mathrm{n}$ & $\%$ & $\mathrm{n}$ & $\%$ & \\
\hline Correct & 10 & 100 & 0 & 0 & 10 & 100 & $<0.001 \dagger$ \\
\hline Incorrect & 24 & 82.8 & 5 & 17.2 & 29 & 100 & \\
\hline
\end{tabular}

*Four students were not included in the analysis due to missing post-simulation training data on all three questions. $†$ McNemar's Test 
Global Journal of Reproductive Medicine

Table 2: Assessment of Students' Confidence in Knowledge and Abilities. $(n=39)$.

\begin{tabular}{|c|c|c|c|}
\hline $\begin{array}{c}\text { I feel confident in my knowledge } \\
\text { of the stages of labor. }\end{array}$ & Pre-Simulation & Post-Simulation & P-Value \\
\hline $\begin{array}{c}\text { I feel confident in my knowledge } \\
\text { of the cardinal movements of } \\
\text { labor. }\end{array}$ & Somewhat disagree (2,-2) & Strongly agree (2,0) & $<0.001$ \\
\hline $\begin{array}{c}\text { I feel ready to participate in a } \\
\text { vaginal delivery independently. }\end{array}$ & Somewhat disagree (2,-2) & Somewhat agree (2,-2) & $<0.001$ \\
\hline $\begin{array}{c}\text { I feel ready to participate in a } \\
\text { vaginal delivery with resident or } \\
\text { attending supervision }\end{array}$ & Somewhat agree (2,-1) & Strongly agree $(2,-2)$ & $<0.001$ \\
\hline
\end{tabular}

Median value on a 5 point scale: strongly agree (2), agree(1), neutral(0), disagree(-1), strongly disagree(-2), and range. Wilcoxon signed rank test.

Table 3: Post-simulation assessment of the effectiveness of the mechanical birth simulator $(n=43)$.

\begin{tabular}{|c|c|c|c|c|c|}
\hline & Strongly agree & Agree & Neutral & Disagree & Strongly disagree \\
\hline $\begin{array}{c}\text { Participating in } \\
\text { the simulation was } \\
\text { helpful. }\end{array}$ & 43 & 0 & 0 & 0 & 0 \\
\hline $\begin{array}{c}\text { Participating in the } \\
\text { simulation helped } \\
\text { me understand the } \\
\text { process of labor. }\end{array}$ & 39 & 4 & 0 & 0 & 0 \\
\hline $\begin{array}{c}\text { Participating in the } \\
\text { simulation helped } \\
\text { me understand pelvic } \\
\text { anatomy. }\end{array}$ & 26 & 17 & 0 & 15 & 0 \\
\hline $\begin{array}{c}\text { I would have gotten } \\
\text { the same education } \\
\text { from a lecture or } \\
\text { discussion. }\end{array}$ & 3 & 0 & 6 & & 0 \\
\hline $\begin{array}{c}\text { I would recommend } \\
\text { continuing the use of } \\
\text { the labor simulation } \\
\text { during the third year } \\
\text { rotation. }\end{array}$ & 42 & 1 & 0 & & 0 \\
\hline
\end{tabular}

Table 4:Post-simulation assessment of the effectiveness of the mechanical birth simulator $(n=43)$.

\begin{tabular}{|c|c|c|c|c|c|}
\hline & $\begin{array}{l}\text { Strongly } \\
\text { agree }\end{array}$ & Agree & Neutral & Disagree & $\begin{array}{l}\text { Strongly } \\
\text { disagree }\end{array}$ \\
\hline Participating in the simulation was helpful. & 43 & 0 & 0 & 0 & 0 \\
\hline Participating in the simulation helped me understand the process of labor. & 39 & 4 & 0 & 0 & 0 \\
\hline Participating in the simulation helped me understand pelvic anatomy. & 26 & 17 & 0 & 0 & 0 \\
\hline I would have gotten the same education from a lecture or discussion. & 3 & 0 & 6 & 15 & 19 \\
\hline $\begin{array}{l}\text { I would recommend continuing the use of the labor simulation during the } \\
\text { third year rotation. }\end{array}$ & 42 & 1 & 0 & 0 & 0 \\
\hline
\end{tabular}

Changes in knowledge of stages of labor, types of obstetric lacerations, and cardinal movements of labor between the preand post-simulation questionnaire are given in Table 1. All three questions showed a statistically significant improvement post-simulation. Similarly, all questions assessing student selfconfidence in knowledge of stages of labor, knowledge of cardinal movements of labor, and readiness to participate in a vaginal delivery with and without supervision showed a statistically significant improvement on the post-simulation questionnaire (Table 2). Students were very supportive in their evaluation of the simulation training (Table 3). All students strongly agreed that the simulation was helpful. All students either strongly agreed or somewhat agreed that the simulation helped them understand the process of labor and to understand pelvic anatomy. Most students felt that a lecture would not have provided the same education. Finally, all students thought that the labor simulation should be continued as part of the third year medical curriculum (Table 4).

\section{Discussion}

The use of a simple and relatively inexpensive birth simulator is a readily available solution to the problems of patient access and liability concerns during undergraduate medical education. We wanted to see if a simple, inexpensive labor simulator could be 
used to instruct medical students. This study demonstrates that it is an effective method of teaching third and fourth year medical students during their obstetrics and gynecology clerkships. The students had significant improvement in their knowledge of all areas assessed. Additionally, their own assessment of their knowledge and skills was significantly improved postsimulation. Finally, they uniformly felt the exercise was valuable. Previous studies have shown similar results though most used more elaborate, more expensive, electronic simulators $[1,3,4]$. Simulators have consistently resulted in increased student knowledge and confidence though their use is relatively new. The high cost of electronic, automated, high fidelity simulators may have limited their widespread adoption. Our study shows that a simple, low fidelity mechanical birthing simulator is an effective teaching tool that was well received by the students.

The primary strength of our study is that our data show consistent improvements in all measures of knowledge and confidence with the use of the simulator. Furthermore, in our post-simulation survey, the students felt they learned more by using the simulator than a lecture alone would have offered. Their written comments were uniformly positive. Our study has several limitations. We had a relatively small sample size. Secondly, there was no control group of students who did not participate in the educational initiative. We only assessed those who tried the new simulator. Additionally, in the student population there were varying degrees of prior obstetrical knowledge depending on their past rotations, which could have biased the results. The same attending physician administered the examinations and performed the simulation training, which could have potentially biased the study. We tried to minimize this by clear instructions and collecting no identifying data or dates on the surveys. Simulator training is being used more and more in graduate medical education. It provides a hands-on way to learn complex interventions with no risk to the patient, while providing a forum for feedback and improvement. We believe it should be routinely used for undergraduate medical education, too. This study adds to the growing literature that shows its efficacy. Our data show that a simple and inexpensive mechanical model can significantly enhance medical student learning.

\section{References}

1. Jude D, Gilbert G, Magrane D (2006) Simulation training in the obstetrics and gynecology clerkship. Am J Obstet Gynecol 195(5): 1489-1492.

2. Sabourin JN, Van Thournout R, Jain V, Demianczuk N (2014) Flood C Confidence i performing normal vaginal delivery in the obstetrics clerkship: a randomized trial of two simulators. J Obstet Gynaecol Can 36(7): 620-627.

3. Dayal AK, Fisher N, Magrane D, Goffman D, Bernstein P, et al. (2009) Simulation training improves medical students learning experiences when performing real vaginal deliveries. Simul Healthc 4(3): 155-159.

4. Holmström SW, Downes K, Mayer JC, Learman LA (2011) Simulation training in an obstetric clerkship; a randomized controlled trial. Obstet and Gynecol 118(3): 649-654.

\section{Your next submission with Juniper Publishers will reach you the below assets}

- Quality Editorial service

- Swift Peer Review

- Reprints availability

- E-prints Service

- Manuscript Podcast for convenient understanding

- Global attainment for your research

- Manuscript accessibility in different formats

( Pdf, E-pub, Full Text, Audio)

- Unceasing customer service

Track the below URL for one-step submission https://juniperpublishers.com/online-submission.php 